\title{
Yapay Zeka ve Sağlıkta Yapay Zekanın Kullanımına Yönelik Sağlık Bilimleri Fakültesi Öğrencilerinin Görüşleri
}

\section{Artificial Intelligence and The Use of Artificial Intelligence in Health: Opinions of Health Sciences Students}

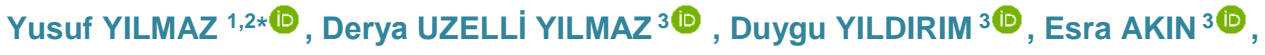 \\ Derya ÖZER KAYA4뭉
}

\author{
${ }^{1}$ McMaster Üniversitesi, Sağılık Bilimleri Fakültesi, Tıp Bölümü, Hamilton, Ontario, Kanada \\ ${ }^{2}$ Ege Üniversitesi, Tıp Fakültesi, Tıp Eğitimi Anabilim Dalı, İzmir, Türkiye \\ ${ }^{3}$ Izmir Katip Çelebi Üniversitesi, Sağlık Bilimleri Fakültesi, Hemşirelik Bölümü, İzmir, Türkiye \\ ${ }^{4}$ İzmir Katip Çelebi Üniversitesi, Sağlık Bilimleri Fakültesi, Fizyoterapi ve Rehabilitasyon Bölümü, İzmir, Türkiye
}

\begin{abstract}
Ö ZE T
Amaç: Bu araştırma, yapay zeka ve sağlıkta yapay zekanın kullanımına yönelik sağlık bilimleri fakültesi öğrencilerinin görüşlerinin belirlenmesi amacı ile yapılmıştır.

Materyal-Metot: Tanımlayıcı tipteki bu araştırma, Mayıs-Temmuz 2020 tarihleri arasında, İzmir ilinde yer alan bir üniversitenin Sağlık Bilimleri Fakültesi hemşirelik ( $n=182)$, fizyoteretapi ve rehabilitasyon $(n=191)$ ve beslenme ve diyetetik ( $n=32$ ) bölümünde öğrenim gören 405 sağlık bilimleri öğrencisinin katılımı ile gerçekleştirilmiştir. Araştırma verileri, Yapay Zeka Farkındalık Anketi ile toplanmıştır. Nitel veriler tematik içeriz analizi yöntemiyle değerlendirilirken, niceliksel verilerin analizinde tanımlayıcı istatistikler kullanılmıştır.
\end{abstract}

Bulgular: Araştırma bulguları; öğrencilerin yarıya yakın kısmı (\%47,9, n=194) sağlıkta yapay zeka kavramı ve çoğunluğunun $(\% 75,6, n=306)$ günlük hayatta yapay zeka ile desteklenen programlar hakkında bilgi sahibi olduklarını, yarısından fazlasının sağlıkta yapay zeka kullanımı hakkında bilgi sahibi olduklarını $(\% 55,8, n=226)$ ve büyük çoğunluğunun (\%92, n=372) bilgiye sosyal medyadan ulaştıklarını gösterdi. Öğrenciler sağlıkta yapay zeka kullanımı ile ilgili görüşlerini sağlıkta yapay zeka kullanımına yönelik olumlu görüşler, olumsuz görüşler, endişeler ve bilgi eksikliği temaları ile ifade etti. Öğrenciler sağlıkta yapay zeka kullanımına yönelik uygulama önerileri arasında; tıbbi hataların önlenmesine yönelik uygulamalar, klinik karar vermeyi kolaylaştıracak uygulamalar, sağlık profesyonellerinin iş yükünü azaltmaya yardımcı uygulamalar ve robotik uygulamalar yer aldı.

Sonuç: Araştırma sonucunda Sağlık Bilimleri Fakültesi öğrencilerinin yapay zeka ve sağlıkta yapay zeka kullanımının farkında oldukları ve yapay zeka araçlarının kullanmak istedikleri ancak bu konuda endişelerinin ve bilgi eksikliğinin olduğu görülmüştür. Geleceğin sağlık profesyonellerini, yapay zeka teknolojilerine hazırlamak için eğitim müfredatında yapay zeka ile ilgili içeriklerin dahil edilmesinin önemli olduğu düşünülmektedir.

Anahtar Kelimeler: Yapay zeka, sağlık, makine öğrenmesi, farkındalık, öğrenci görüşleri

Alınış / Received: 10.06.2021 Kabul / Accepted: 31.08.2021 Online Yayınlanma / Published Online: 20.12.2021 


\title{
0000000
}

\author{
A B S T R A C T
}

Objective: This study aimed to determine the opinions of students from health sciences faculty on artificial intelligence $(\mathrm{Al})$ and the use of $\mathrm{Al}$ in health.

Material and Method: The study utilized a survey design and was conducted with 405 health sciences faculty students participation from nursing $(n=182)$, physiotherapy and rehabilitation $(n=191)$, and nutrition and dietetics $(\mathrm{n}=32)$ departments. Research data were collected using an Al opinions questionnaire. Qualitative data were analyzed thematically, and descriptive statistics were used in the analysis of quantitative data.

Results: The students stated that almost half $(47.9 \%, \mathrm{n}=194)$ have knowledge toward $\mathrm{Al}$ in health, the majority $(75.6 \%, \mathrm{n}=306)$ were aware of the everyday online applications supported by $\mathrm{Al}$, more than half of them knew the use of $\mathrm{Al}$ in health $(55.8 \%, \mathrm{n}=226)$ and the majority of the students $(92 \%, \mathrm{n}=372)$ indicated that they learn more about Al from social media. Students expressed their views on the use of $\mathrm{Al}$ in health with the themes of positive opinions, negative opinions, concerns, and lack of knowledge about the use of Al in health. The students suggested applications to prevent medical errors, applications to facilitate clinical decision making.

Conclusions: This study concludes that health science students are aware of the use of $\mathrm{Al}$ and $\mathrm{Al}$ in health and they want to use Al tools in their education but they have concerns and lack of knowledge on Al. The curriculum in health sciences education should include Al-related content to prepare future healthcare professionals ready for Al technologies.

\section{Giriş}

Yapay zeka, alanın öncü isimlerinden John McCarthy tarafından "Zeki makineler özellikle de, zeki bilgisayar programları yapma bilimi ve mühendisliği" olarak tanımlanmıştır [1]. Makine öğrenimi önemli bir çalışma alanını oluşturan çağdaş yapay zekanın omurgası, bir girdi verildiğinde uygun çıktıları tahmin etmek için büyük veri kümeleri üzerinde bir algoritma eğitimini içerir [2]. Son yıllarda, derin sinir ağlarının, doğal dil işlemenin ve robotik teknolojinin gelişmesiyle yapay zeka alanında büyük ilerlemeler kaydedilmiştir. Örnegin günlük hayatta internet ortamında sesli komut tanıma (Siri Google Asistan), maildeki spam (istenmeyen posta) kutusu, öneriler (youtube video önerisi, alışveriş sitelerindeki ürün önerileri), çeviri programları (Google translate/ çeviri) gibi sıklıkla kullandığımız pek çok araç yapay zeka teknolojisi ile desteklenmektedir [3].

Sağlık hizmetlerinde verilerin karmaşıklığı ve artışı nedeni ile yapay zekanın bu alanda kullanımına dikkat çekilmiştir. Gelecekte yapay zekanın sağığın çeşitli alanlarını önemli ölçüde etkilemesi beklenmektedir ve sağlık hizmetlerinin birçok yönünü iyileştirme potansiyeline sahip olduğu düşünülmektedir [4,5].

Yapay zeka teknolojilerinin sağlık alanında erken teşhis, doğru tanılama, klinik karar verme, sağlığı koruyup sürdürme gibi alanlarda kullanıldığı bilinmektedir [5]. Son yıllarda, yapay zekanın sağlıkta pek çok alanda kullanım örnekleri karşımıza çıkmaktadır. Bu uygulamalara, Birleşik Krallık'ta yapay zeka sohbet botu şeklinde bir yapay zeka klinisyeninin oluşturulması örnek verilebilir [6]. Ayrıca Çin'de radyologlar beyin tomografisi taramalarını ve $\mathrm{x}$-ışınlarını okurken tıbbi tanıyı iyileştirmek ve akciğer kanseri hastalarında şüpheli lezyonları ve nodülleri belirlemek için yapay zeka teknolojisini kullanmaktadırlar [7]. Amerika'da yapay zeka platformunu onkoloji tedavilerini analiz etmek ve yapay zekanın daha az yan etkiye sahip ilaçlar tasarlayıp tasarlayamayacağını görmek için kullanıldığı bilinmektedir $[5,8,9]$. Bu örnek uygulamalar, yapay zekanın, bilgi işleyebilme yeteneği ile sağlıkta 
yanlış tanılama ve tıbbi hatalar sorununu büyük ölçüde çözebileceğini ve verimliliği arttırmak için tıbbi malpraktis oranını azaltıcı rolü olan araçlar olarak kullanılabileceğini bildirmektedir [10,11]. Sağlık hizmeti sunumunda ve tıbbi araştırmalarda yapay zeka tekniklerinin potansiyel rolleri daha belirgin hale gelse de, pek çok yapay zeka uygulamasının tam olgunluğu henüz gerçekleşmemiştir. Bu nedenle, gelecekte yapay zekanın insan vizyonu, dil işleme ve bağlama özgü akıl yürütme özelliklerinin ne tür sorunları ya da zorlukları beraberinde getireceği henüz belirsizdir [8,9].

Yapay zeka teknolojisindeki gelişmeler göz önüne alındığında, sağlık profesyonellerinin klinik ortamında farklı teknolojiler ve ilgili uygulamalarla karşılaşacaklarına şüphe yoktur. Geleceğin sağlık profesyonelleri olan öğrencilerin eğitimlerini tamamlayarak sağlık profesyoneli olarak kariyerlerine başlayacakları sırada, klinik ortamlarında çeşitli yapay zeka araçlarının kullanılacağı düşünülmektedir. $\mathrm{Bu}$ nedenle, eğitimcilerin ve yöneticilerin, geleceğin sağlık profesyonellerini yapay zeka teknolojilerinden yararlanmaları konusunu titizlikle ele almaları gerekmektedir. Yurtdışında pek çok sağlık bilimleri yüksek öğretim kuruluşları, yapay zeka konusunun sağlık hizmetleri profesyonel eğitiminin her seviyesine entegre edilmesini duyurmuştur [12-16]. Öte yandan, tıp fakültesi öğrencileri ile yapılan bir çalışmada araştırmaya katılan öğrencilerin çoğunluğu, yapay zeka öğrenmenin kariyerleri için çok önemli olduğunu belirtmiştir [17].

Yapay zekayı öğrenciler, sağlık hizmetleri ve profesyonel organizasyon genelinde sağlık bilimleri eğitimine dahil etme arzusu, böyle bir müfredatın nasıl geliştirilmesi gerektiği konusunda daha fazla araştırma yapılması intiyacını vurgulamaktadır. Literatürde tıp öğrencilerinin yapay zekanın sağılkta kullanımına yönelik görüşleri [18] bulunmasına rağmen diğer sağlık bilimleri öğrencilerinin görüşlerine yönelik çalışmalar daha kısıtlıdır. Aynı zamanda sağlık bilimleri öğrencilerinin yapay zeka ile ilgili temel bilgilerini, görüşlerini ve endişelerini anlamak, sağlıkta yapay zeka uygulamaları konusunda farkındalıklarının artııımasını ve bu konuda verilmesi gereken eğitimin şekillendirilmesini sağlayabilir. $\mathrm{Bu}$ bağlamda araştırma, sağlık bilimleri fakültesi öğrencilerinin (hemşirelik, fizyoterapi ve rehabilitasyon, beslenme ve diyetetik) yapay zeka ve sağlıkta yapay zeka kullanımına yönelik görüşlerinin belirlenmesi amacı ile gerçekleştirilmiştir.

\section{Materyal ve Metot}

\section{Araştırmanın Tipi}

Araşıırma tanımlayıcı tipte gerçekleştirilmiştir. Araştırmanın evrenini, 2019-2020 Eğitim Öğretim yılında İzmir'de bulunan bir devlet üniversitesinin Sağlık Bilimleri Fakültesi hemşirelik, fizyoterapi ve rehabilitasyon, beslenme ve diyetetik bölümlerinde öğrenim gören öğrenciler $(\mathrm{N}=1354)$ oluşturmuştur. Araştırmada örneklem seçimine gidilmemiş olup, araştırmanın yapıldığı tarihlerde çalışmaya katılmayı kabul eden öğrenciler $(n=405)$ araştırmanın örneklemine dahil edilmiştir.

\section{Veri Toplama Araçları}

Araştırma verileri "Yapay Zeka Farkındalık Anketi" ile toplanmıştır. Araştırmacılar tarafından ilgili literatür incelenerek hazırlanan anket dört bölümden oluşmaktadır. Birinci bölüm olan tanıtıcı bilgiler bölümü, öğrencilerin sosyo-demografik bilgilerini öğrenmeyi amaçlayan toplam 3 sorudan oluşmaktadır. Anketin ikinci bölümü, öğrencilerin yapay zeka kullanım durumu ve internet kullanım durumunu sorgulayan toplam 7 sorudan oluşmaktadır. Üçüncü bölüm olan anket maddeleri Likert tipte toplamda 27 sorudan oluşmaktadır. Anket maddeleri, "Kesinlikle katılmıyorum (1)", "Katılmıyorum (2), Kararsızım (3), Katılıyorum (4) ve Kesinlikle Katılıyorum (5) ifadelerinden oluşmuştur. Dördüncü bölüm olan açık uçlu sorular bölümü öğrencilerin gelecekteki yapay zeka uygulamalarına yönelik düşüncelerini sorgulayan 3 sorudan oluşmaktadır. Anket sorularına sağlık bilimleri, biyoistatistik ve tıbbi bilişim, bilgisayar ve öğretim teknolojileri ile tıp eğitimi alanlarından toplam 7 uzman, dörtlü Likert puanlamasına dayalı olarak (1: Uygun değil; 2: Biraz uygun, revizyon gerekli; 3: Oldukça uygun, küçük değişiklikler gerekli; 4: Oldukça uygun) uzmanlık görüşü vermiştir. Anket maddelerinin çalışma amacına uygunluğu ile ilgili gerekli düzeltmeler yapılarak ankete son hali verilmiştir. Anket uygulanmadan önce, 3 Sağlık Bilimleri Fakültesi öğrencisine uygulanmış ve ön pilot çalışması gerçekleştirilmiştir.

\section{Verilerin Toplanması}

Veriler, Mayıs-Temmuz 2020 tarihleri arasında öğrencilerin gönüllü katılımları sağlandıktan sonra, çevrimiçi veri toplama yöntemi kullanılarak toplanmıştır. Öğrenciler, araştırmanın amacını açıklayan bilgilendirilmiş onam sayfasını kabul etmelerinin ardından anket sorularını görüntüleyebilmişlerdir. Her anket formunun doldurulma süresi yaklaşık 10 dakika sürmüştür. Verilerin toplanma süreci çevrimiçi olarak takip edilmiştir. 


\section{Verilerin Değerlendirilmesi}

Araştırmanın amacına uygun olarak toplanan veriler araştırmacı tarafından Statistical Package for the Social Sciences (SPSS) version 26.0 (SPSS Inc, Chicago, IL, USA) (19) istatistik paket programı kullanılarak gerçekleştirilmiştir. Tanımlayıcı verilerin analizinde sayı, yüzde, ortalama, standart sapma kullanılmıştır. Kategorik değişkenler frekanslar ve yüzdeler ile tanımlanmıştır. Nitel verilerin analizinde tematik analiz yöntemi kullanılmıştır. Öğrencilerin sağlıkta yapay zeka kullanımına yönelik görüşleri ve önerileri iki araştırmacı tarafından bağımsız olarak okunmuş ve kavramsallaştıııııştır. Ortaya çıkan kavramsal kodlar düzenlenip, veriyi açıklayan temalar saptanmıştır.

\section{Araştırmanın Etik Yönü}

Araştırmanın yürütülebilmesi için bilimsel araştırmanın yürütüldüğü üniversite etik kurulundan izin (Sayı No: 2020-GOKAE-0101) ve araştırmanın yapılacağı Fakülte Dekanlığı'ndan yazılı izin alınmıştır. Ayrıca, araştırmaya katılan öğrencilere çevrimiçi ortamda araştırmanın amacı hakkında bilgi verilerek bilgilendirilmiş onamları alınmıştır.

\section{Araştırmanın Sınırılıkları}

Araştırma İzmir ilindeki bir üniversitenin Sağlık Bilimleri Fakültesi'nde öğrenim gören, araştırmaya katılmayı kabul eden hemşirelik, fizyoterapi ve rehabilitasyon, beslenme ve diyetetik bölümü öğrencileri ile sınırlıdır.

\section{Bulgular}

Araştırmaya katılan öğrencilerinin yaş ortalamasının $20,92 \pm 1,45$ yıl ve çoğunluğunun kadın $(\% 78,8)$ olduğu belirlenmiştir. Öğrencilerin \%47,2'sinin $(n=191)$ fizyoterapi ve rehabilitasyon, \%44,9'unun $(n=182)$ hemşirelik ve \%7,9'unun $(n=32)$ beslenme ve diyetetik bölümünde öğrenim görmekte olduğu belirlenmişstir. Öğrencilerin \%38'i $(n=154)$ ikinci sınıf öğrencisidir. İnternet teknolojisi kullanma durumu ortalamasının ( 0 hiç kullanmam, 10 yakından ilgilenirim ve kullanırım): 7,27士1,83 olduğu ve \%31,1'inin ( $n=126)$ günlük internet kullanma saatinin 4 saatten fazla olduğu saptanmıştır (Tablo 1).

Öğrencilerin \%47,9'u ( $n=194)$ yapay zeka kavramı hakkında kısmen bilgi sahibi olduğunu ifade etmiştir. Öğrencilerin \%75,6'sı ( $\mathrm{n=306)}$ internet ortamında yapay zeka ile desteklenen programlar hakkında bilgi sahibi olduğunu belirtirken, \% 55,8'i $(n=226)$ yapay zekanın sağlıkta kullanımı hakkında kısmen bilgi sahibi olduğunu bildirmiştir. Öğrencilerin \%92'si $(n=372)$ bu bilgileri sosyal medyadan edindiğini ifade etmiştir. Çalışmamızdaki öğrencilerin \%47,7'si $(n=193)$ yapay zekanın kullanılığı bir uygulamayı kullandığını belirtmiştir (Tablo 1).

Tablo 1. Öğrencilerin Tanıtıcı Bilgilerinin Dağılımı (n=405)

\begin{tabular}{lcc}
\hline Değişkenler & Sayı (n) & Yüzde (\%) \\
\hline Yaş ortalaması: 20,92+1,45 & & \\
\hline Cinsiyet & 319 & 78,8 \\
Kadın & 86 & 21,2 \\
Erkek & & \\
\hline Bölüm & 182 & 44,9 \\
Hemşirelik & 191 & 47,2 \\
Fizyoterapi ve rehabilitasyon & 32 & 7,9 \\
Beslenme ve diyetetik & & \\
\hline Sınıf & 115 & 28,4 \\
Birinci sınıf & 154 & 38,0 \\
İkinci sınıf & 78 & 19,3 \\
Üçüncü sınıf & 58 & 14,3 \\
Dördüncü sınıf & &
\end{tabular}




\begin{tabular}{|c|c|c|}
\hline $\begin{array}{l}\text { Internet teknolojisi kullanma } \\
\text { ortalaması ( } 0 \text { hiç kullanmam, } 10 \text { yakından } \\
\text { ilgilenirim ve kullanırım): } 7,27 \pm 1,83\end{array}$ & & \\
\hline Günlük internet kullanım süresi & & \\
\hline 30 dakika ile 1 saat arası & 10 & 2,47 \\
\hline 1 saat ile 2 saat arası & 42 & 10,37 \\
\hline 2 saat ile 3 saat arası & 110 & 27,16 \\
\hline 3 saat ile 4 saat arası & 117 & 28,89 \\
\hline 4 saatten fazla & 126 & 31,11 \\
\hline \multicolumn{3}{|l|}{$\begin{array}{l}\text { Yapay zeka kavramı hakkında bilgi sahibi olma } \\
\text { durumu }\end{array}$} \\
\hline Evet & 192 & 47,4 \\
\hline Hayır & 19 & 4,7 \\
\hline Kısmen & 194 & 47,9 \\
\hline \multicolumn{3}{|l|}{$\begin{array}{l}\text { İnternet ortamında yapay zeka ile desteklenen } \\
\text { programlar hakkında bilgi sahibi olma durumu }\end{array}$} \\
\hline \multicolumn{3}{|l|}{ Evet } \\
\hline Hayır & 306 & 75,56 \\
\hline \multirow[t]{2}{*}{ Kısmen } & 12 & 2,96 \\
\hline & 87 & 21,48 \\
\hline \multicolumn{3}{|l|}{$\begin{array}{l}\text { Yapay zekanın sağlıkta kullanımı hakkında } \\
\text { bilgi sahibi olma durumu }\end{array}$} \\
\hline Evet & 141 & 34,8 \\
\hline Hayır & 38 & 9,4 \\
\hline Kısmen & 226 & 55,8 \\
\hline \multicolumn{3}{|l|}{$\begin{array}{l}\text { Yapay zeka hakkında bilgi alma kaynağı } \\
\text { (Yüzdelikler örneklem içerisinde verilmiştir) }\end{array}$} \\
\hline Sosyal medya & 372 & 92 \\
\hline Yazılı/Görsel basın & 132 & 33 \\
\hline Derslerden & 75 & 19 \\
\hline Arkadaşlardan/Aileden & 140 & 35 \\
\hline Araştırma & 4 & 1 \\
\hline Bilimsel etkinlik & 2 & 0 \\
\hline \multicolumn{3}{|l|}{$\begin{array}{l}\text { Yapay zekanın kullanıldığı bir uygulamayı } \\
\text { kullanma durumu }\end{array}$} \\
\hline Evet & 193 & 47,66 \\
\hline Hayır & 87 & 21,48 \\
\hline Bilmiyorum & 125 & 30,86 \\
\hline Toplam & 405 & 100,0 \\
\hline
\end{tabular}


Öğrencilerin yapay zeka ve sağlıkta yapay zeka kullanımına ilişkin görüşlerini içeren maddeler arasından "Mesleğime yönelik yapay zeka ile ilgili gelişmeleri takip etmek önemlidir." $(3,80 \pm 1,06)$ en yüksek puan almıştır. Bu maddeyi "Yapay zeka uygulamaları etik yönden de eğitilmelidir." $(3,76 \pm 1,10)$, "Yapay zeka uygulamaları, veriyi işleyerek bundan anlamlar ve öneriler çıkarır." $(3,75 \pm 1,05)$ ve "Yapay zeka sağlık alanında kullanılmalıdır." $(3,71 \pm 1,09)$ maddeleri izlemektedir. "Yapay zeka sistemleri ırkçı, cinsiyetçi, ayrımcı kararlar alarak toplumu olumsuz etkiler." $(2,43 \pm 1,07)$ maddesi en düşük puan ortalamasına sahiptir (Tablo 2). Ayrıca Tablo 2 Likert maddelere verilen her bir cevap için ısı haritasını da göstermektedir.

Tablo 2. Yapay Zeka Farkındalık Anketi Madde Puan Ortalamalarının Dağılımı

\begin{tabular}{|c|c|c|c|c|c|c|}
\hline Madde & $\begin{array}{l}1 \\
\% \\
\text { (n) }\end{array}$ & $\begin{array}{l}2 \\
\% \\
\text { (n) }\end{array}$ & $\begin{array}{l}3 \\
\% \\
(n)\end{array}$ & $\begin{array}{l}4 \\
\% \\
(n)\end{array}$ & $\begin{array}{l}5 \\
\% \\
(n)\end{array}$ & Ort士SS \\
\hline $\begin{array}{l}\text { Mesleğime yönelik yapay zeka ile ilgili } \\
\text { gelişmeleri takip etmek önemlidir. }\end{array}$ & $\begin{array}{c}7 \\
(28)\end{array}$ & $\begin{array}{c}5 \\
(20)\end{array}$ & $\begin{array}{c}12 \\
(48)\end{array}$ & $\begin{array}{c}54 \\
(220)\end{array}$ & $\begin{array}{c}22 \\
(89)\end{array}$ & $3,80 \pm 1,06$ \\
\hline $\begin{array}{l}\text { Yapay zeka uygulamaları etik yönden de } \\
\text { eğitilmelidir. }\end{array}$ & $\begin{array}{c}7 \\
(30)\end{array}$ & $\begin{array}{c}5 \\
(21)\end{array}$ & $\begin{array}{l}15 \\
(61)\end{array}$ & $\begin{array}{c}48 \\
(196)\end{array}$ & $\begin{array}{c}24 \\
(97)\end{array}$ & $3,76 \pm 1,10$ \\
\hline $\begin{array}{l}\text { Yapay zeka uygulamaları, veriyi işleyerek } \\
\text { bundan anlamlar ve öneriler çıkarır. }\end{array}$ & $\begin{array}{c}7 \\
(30)\end{array}$ & $\begin{array}{c}5 \\
(21)\end{array}$ & $\begin{array}{c}10 \\
(40)\end{array}$ & $\begin{array}{c}60 \\
(243)\end{array}$ & $\begin{array}{c}18 \\
(71)\end{array}$ & $3,75 \pm 1,04$ \\
\hline Yapay zeka sağlık alanında kullanılmalıdır. & $\begin{array}{c}7 \\
(29)\end{array}$ & $\begin{array}{c}7 \\
(28)\end{array}$ & $\begin{array}{c}14 \\
(58)\end{array}$ & $\begin{array}{c}51 \\
(206)\end{array}$ & $\begin{array}{l}21 \\
(84)\end{array}$ & $3,71 \pm 1,09$ \\
\hline $\begin{array}{l}\text { Sağlık alanında yapay zeka kullanımına } \\
\text { ilişkin gelişmeler beni heyecanlandırıyor. }\end{array}$ & $\begin{array}{c}7 \\
(28)\end{array}$ & $\begin{array}{c}7 \\
(29)\end{array}$ & $\begin{array}{l}21 \\
(84)\end{array}$ & $\begin{array}{c}43 \\
(176)\end{array}$ & $\begin{array}{c}22 \\
(88)\end{array}$ & $3,66 \pm 1,11$ \\
\hline $\begin{array}{l}\text { Yapay zeka ifadesi bana robot sistemleri } \\
\text { çağrıştırmaktadır. }\end{array}$ & $\begin{array}{c}7 \\
(29)\end{array}$ & $\begin{array}{c}8 \\
(31)\end{array}$ & $\begin{array}{c}12 \\
(49)\end{array}$ & $\begin{array}{c}59 \\
(239)\end{array}$ & $\begin{array}{c}14 \\
(57)\end{array}$ & $3,65 \pm 1,05$ \\
\hline $\begin{array}{l}\text { Yapay zekanın karar destegi verme özelliği, } \\
\text { sağlık çalışanlarına yardımcı olur. }\end{array}$ & $\begin{array}{c}7 \\
(27)\end{array}$ & $\begin{array}{c}8 \\
(33)\end{array}$ & $\begin{array}{l}21 \\
(84)\end{array}$ & $\begin{array}{c}50 \\
(201)\end{array}$ & $\begin{array}{c}15 \\
(60)\end{array}$ & $3,58 \pm 1,05$ \\
\hline $\begin{array}{l}\text { Yapay zeka sistemleri, tıbbi hata yapma } \\
\text { riskini azaltır. }\end{array}$ & $\begin{array}{c}5 \\
(22)\end{array}$ & $\begin{array}{c}8 \\
(34)\end{array}$ & $\begin{array}{c}27 \\
(111)\end{array}$ & $\begin{array}{c}43 \\
(176)\end{array}$ & $\begin{array}{l}15 \\
(62)\end{array}$ & $3,55 \pm 1,03$ \\
\hline $\begin{array}{l}\text { Yapay zeka kullanarak hastalara daha iyi } \\
\text { sağlık hizmeti sunabilirim. }\end{array}$ & $\begin{array}{c}7 \\
(29)\end{array}$ & $\begin{array}{c}6 \\
(26)\end{array}$ & $\begin{array}{c}25 \\
(101)\end{array}$ & $\begin{array}{c}48 \\
(194)\end{array}$ & $\begin{array}{c}14 \\
(55)\end{array}$ & $3,54 \pm 1,04$ \\
\hline $\begin{array}{l}\text { Sağlık çalışanlarının değer sistemi } \\
\text { (özgecilik, özerklik vb.), yapay zeka } \\
\text { sistemlerine kodlanmalıdır. }\end{array}$ & $\begin{array}{c}8 \\
(34)\end{array}$ & $\begin{array}{c}9 \\
(35)\end{array}$ & $\begin{array}{c}20 \\
(83)\end{array}$ & $\begin{array}{c}45 \\
(183)\end{array}$ & $\begin{array}{c}17 \\
(70)\end{array}$ & $3,54 \pm 1,13$ \\
\hline $\begin{array}{l}\text { Mesleğime yönelik yapay zeka uygulamaları } \\
\text { hakkında sohbet etmek hoşuma gider. }\end{array}$ & $\begin{array}{c}9 \\
(37)\end{array}$ & $\begin{array}{c}8 \\
(34)\end{array}$ & $\begin{array}{c}21 \\
(86)\end{array}$ & $\begin{array}{c}46 \\
(187)\end{array}$ & $\begin{array}{c}15 \\
(61)\end{array}$ & $3,50 \pm 1,13$ \\
\hline $\begin{array}{l}\text { Yapay zeka sistemlerinin, kendilerine } \\
\text { öğretilmediği sürece etik anlayışları yoktur. }\end{array}$ & $\begin{array}{c}7 \\
(30)\end{array}$ & $\begin{array}{c}11 \\
(44)\end{array}$ & $\begin{array}{c}26 \\
(105)\end{array}$ & $\begin{array}{c}37 \\
(150)\end{array}$ & $\begin{array}{c}19 \\
(76)\end{array}$ & $3,49 \pm 1,14$ \\
\hline $\begin{array}{l}\text { Yapay zekanın, insanların ne hissettiklerini } \\
\text { tahmin edebilmesi mesleğimi yapmamda } \\
\text { fırsatlar sunar. }\end{array}$ & $\begin{array}{c}9 \\
(36)\end{array}$ & $\begin{array}{c}10 \\
(40)\end{array}$ & $\begin{array}{c}25 \\
(103)\end{array}$ & $\begin{array}{c}42 \\
(169)\end{array}$ & $\begin{array}{c}14 \\
(57)\end{array}$ & $3,42 \pm 1,12$ \\
\hline Kendi kendine öğrenen yapay zeka & 8 & 15 & 22 & 39 & 17 & $3,41 \pm 1,16$ \\
\hline
\end{tabular}


uygulaması geliştirmek ilgimi çeker.

\begin{tabular}{|c|c|c|c|c|c|}
\hline (31) & (61) & (89) & (157) & (67) & \\
\hline 9 & 7 & 27 & 45 & 11 & $3,41 \pm 1,08$ \\
\hline (38) & (30) & (109) & (184) & (44) & \\
\hline 9 & 12 & 27 & 35 & 17 & $3,38 \pm 1,16$ \\
\hline (36) & (49) & (111) & (142) & (67) & \\
\hline 9 & 14 & 24 & 37 & 16 & $3,36 \pm 1,18$ \\
\hline (38) & (56) & (96) & (151) & (64) & \\
\hline 7 & 11 & 32 & 41 & 9 & $3,35 \pm 1,01$ \\
\hline (27) & (44) & (131) & (168) & (35) & \\
\hline 8 & 14 & 28 & 41 & 8 & $3,27 \pm 1,07$ \\
\hline (34) & (58) & (112) & (168) & (33) & \\
\hline 9 & 15 & 31 & 31 & 13 & $3,25 \pm 1,15$ \\
\hline (38) & (59) & (127) & (127) & (54) & \\
\hline 9 & 22 & 20 & 42 & 6 & $3,15 \pm 1,12$ \\
\hline (37) & (91) & (79) & (172) & (26) & \\
\hline 6 & 28 & 26 & 33 & 7 & $3,08 \pm 1,06$ \\
\hline (24) & (112) & (105) & (135) & (29) & \\
\hline 9 & 22 & 39 & $24(98)$ & 7 & $2,98 \pm 1,04$ \\
\hline (35) & (89) & (156) & & (27) & \\
\hline 11 & 26 & 34 & $20(79)$ & 9 & $2,89 \pm 1,11$ \\
\hline (44) & (107) & (139) & & (36) & \\
\hline 14 & 25 & 33 & $20(81)$ & 8 & $2,82 \pm 1,14$ \\
\hline (57) & (102) & (133) & & (32) & \\
\hline 17 & 32 & 31 & $16(64)$ & 4 & $2,57 \pm 1,06$ \\
\hline (69) & (130) & (127) & & (15) & \\
\hline 20 & 35 & 30 & $9(36)$ & 5 & $2,43 \pm 1,07$ \\
\hline (83) & (143) & (122) & & (21) & \\
\hline
\end{tabular}

Yapay zeka uygulamaları mesleki

becerilerimi zenginleştirir.

Yapay zekanın kullanımın artması, gelecekte

iş bulmamı tehlikeye sokar.

Yapay zeka yaygınlaştıkça sağlık

çalışanlarına olan intiyaç giderek azalacaktır.

Yapay zeka sağlıkta kullanıldığında sağlık

çalışanının kendi kararlarını sorgulamasına

neden olur.

Yapay zekanın kendi kendine öğrenmesi

mesleğimi daha iyi yapabilmek için

kolaylaştırıcıdır.

Yapay zeka desteğiyle aldığım kararlardan

(tanı, bakım, tedavi vb.) yapay zeka da

sorumlu tutulmalıdır.

Yapay zeka, insan beynine benzer şekilde

hissetme, öngörme, karar verme gibi

özelliklere sahiptir.

Yapay zeka, canlı bir organizmadan

yararlanmadan, tümüyle yapay araçlar ile

çalışan bir teknolojidir.

Yapay zekanın sağıkta kullanımıyla

hastaların kendi hastalıklarına yönelik bilgi

edinmesi çalışma ortamında sağlık

çalışanlarına zorluklar çıkarır.

Yapay zeka sebebiyle ileride yapacağım

mesleğim yok olacaktır.

Yapay zeka alanındaki gelişmeler beni

korkutuyor.

Yapay zeka sistemleri, yasal bir birey olarak tanımlanmalıdır.

Yapay zeka sistemleri ırkçı, cinsiyetçi,

ayrımcı kararlar alarak toplumu olumsuz

etkiler.

1: Kesinlikle katılmıyorum, 2: Katılmıyorum, 3: Kararsızım, 4: Katılıyorum, 5: Kesinlikle Katılıyorum. Ort: ortalama; SS: standart sapma

Sağlıkta yapay zeka kullanımına yönelik öğrencilerin görüşleri "Sağlıkta yapay zeka kullanımına yönelik olumlu görüşler" ( $n=3, \% 6,4)$, "Sağlıkta yapay zeka kullanımına yönelik olumsuz görüşler" $(n=3, \% 6,4)$, "Sağlıkta yapay zeka kullanımına yönelik endişeler" $(n=5, \% 10,6)$ ve "Sağlıkta yapay zeka kullanımına yönelik bilgi eksikliği” ( $n=36, \% 76,6)$ şeklinde gruplandırılmıştır (Tablo 3). 
Tablo 3. Sağlıkta Yapay Zeka Kullanımına Yönelik Öğrenci Görüşleri $(n=48)^{*}$

\begin{tabular}{|c|c|}
\hline Tema & Bazı öğrenci ifadeleri \\
\hline $\begin{array}{l}\text { Sağlıkta yapay zeka kullanımına yönelik olumlu } \\
\text { görüşler }(n=3)\end{array}$ & $\begin{array}{l}\text { "Yapay zeka insanlığa zarar vermediği sürece } \\
\text { faydalıdır." } \\
\text { "Yapay zeka kullanımının nerdeyse her alanda } \\
\text { yaygınlaşmasının, günlük hayatta çoğu işi } \\
\text { kolaylaştıracağını ve birçok alanda olduğu gibi } \\
\text { sağlık alanında da ilerleme kaydetmede etkili } \\
\text { olacağını düşünüyorum." }\end{array}$ \\
\hline $\begin{array}{l}\text { Sağlıkta yapay zeka kullanımına yönelik } \\
\text { olumsuz görüşler }(n=3)\end{array}$ & $\begin{array}{l}\text { “Yapay zekayı sevmem. Bu sürecin Dünya'ya } \\
\text { çok ağır bir bedeli olacak.” } \\
\text { "Kendi doğal zekamızı kullanmalıyız. Yapay } \\
\text { zekadan Dünyaya, insanlara hayır gelmez.” }\end{array}$ \\
\hline $\begin{array}{l}\text { Sağlıkta yapay zeka kullanımına yönelik } \\
\text { endişeler }(n=5)\end{array}$ & $\begin{array}{l}\text { "Yapay zeka sağlık çalışanların çalışma } \\
\text { alanlarını sınırlandırıp onları işsiz bırakacaktır." } \\
\text { "Her ne kadar kullanışlı da olsa insan hayatının } \\
\text { bu kadar teknolojiye bağımlı hale çevrilmesi ve } \\
\text { kişisel bilgilerin teknoloji sayesinde kolayca elde } \\
\text { edilebilir duruma gelmesi vs. gibi ilerlemenin } \\
\text { getirdiği olumsuz sonuçlarla karşılaşılabileceği } \\
\text { konusunda endişeli olduğumu belirtmek isterim." }\end{array}$ \\
\hline $\begin{array}{l}\text { Sağlıkta yapay zeka kullanımına yönelik bilgi } \\
\text { eksikliği }(n=36)\end{array}$ & $\begin{array}{l}\text { "4. Sınıfta yapay zekayı kaliteli kullanma ve } \\
\text { doğru fayda sağlama ile ilgili eğitim verilmelidir } \\
\text { bize” }\end{array}$ \\
\hline
\end{tabular}

Öğrencilerin sağlıkta yapay zeka kullanımına yönelik uygulama önerilerinin yer aldığı bulgular Tablo 4'de verilmiştir. Öğrencilerin vermiş olduğu öneriler "Tıbbi hataların önlenmesine yönelik uygulamalar" $(n=4, \% 4,6)$, "Klinik karar vermeyi kolaylaştıracak uygulamalar" $(n=23, \% 26,4)$, "Hastaların hislerini ve düşüncelerini anlamaya yardımcı olabilecek uygulamalar" (n=3, \%3,4), "Hasta takip uygulamaları" ( $n=7, \% 8,0)$, "Hastaların kullanımına yönelik hatırlatıcı uygulamaları" ( $n=13, \% 14,9)$, "Sağlık profesyonellerinin iş yükünü azaltmaya yardımcı uygulamalar" (n=21, \%21,4) ve "Robotik uygulamalar" $(n=16, \% 18,4)$ olarak 7 grupta toplanmıştır. 
Tablo 4. Öğrencilerin sağlıkta yapay zeka kullanımına yönelik uygulama önerileri $(n=87)^{\star}$

\begin{tabular}{lcc}
\hline Öneri & Sayı & Yüzde (\%) \\
\hline Tıbbi hataların önlenmesine yönelik uygulamalar & 4 & 4,6 \\
\hline Klinik karar vermeyi kolaylaştıracak uygulamalar & 23 & 26,4 \\
\hline Hastaların hislerini ve düşüncelerini anlamaya yardımcı olabilecek uygulamalar & 3 & 3,4 \\
\hline Hasta takip uygulamaları & 7 & 8,0 \\
\hline Hastaların kullanımına yönelik hatırlatıcı uygulamaları & 13 & 14,9 \\
\hline Sağlık profesyonellerinin iş yükünü azaltmaya yardımcı uygulamalar & 21 & 24,1 \\
\hline Robotik uygulamalar & 16 & 18,4 \\
\hline *Açı uçlu soruya yanıt veren öğrenci sayıı üzerinden hesaplanmışır. &
\end{tabular}

\section{Tartışma ve Sonuç}

Yapay zekanın günlük hayatımıza her geçen gün daha fazla dahil olduğu gibi, sağlık alanında da bu artış paralel bir eğilim göstermektedir. Yapay zeka ile desteklenen sağlık hizmetleri teknolojilerdeki bu artış nedeniyle, sağlık profesyonellerinin bu teknolojileri uygun şekilde kullanmaları ve bunların hasta bakımı, sağlık sistemi ve toplum üzerindeki etkilerine aşina olmaları gerekmektedir [20]. Bu çalışmada sağlık bilimleri fakültesi öğrencilerinin sağlıkta yapay zeka ile ilgili görüşleri incelenmiştir.

Yapay zeka teknolojisi günlük hayatımızda kullandığımız internet teknolojilerine her geçen gün daha fazla dahil olmaktadır. Araştırmamızdaki öğrencilerin çoğunluğunun $(\% 75,6)$ internet ortamında kullanılan bazı programların yapay zeka ile desteklendiğini bilmektedir ve \%47,7'si yapay zekanın teknolojisinin kullanıldığı bir uygulamayı kullandığını belirtmiştir. Özellikle üniversite öğrencileri vakitlerinin önemli bir kısmını internette geçirmektedirler. Türkiye İstatistik Kurumu (TÜİK)'nun 2020 yılı verilerine göre Türkiye'de 16-74 yaş grubundaki bireylerde internet kullanım oranı \%79,0'dur [21]. Nitekim araştırmamızda yer alan öğrencilerin \%31,1'inin günlük internet kullanma süresinin 4 saat ve üzeri saat olduğu belirlenmiştir. Bu sonuçla benzer şekilde, Öcal ve arkadaşlarının tıp fakültesi öğrencilerinin tıpta yapay zeka ile ilgili düşüncelerini incelediği çalışmasında öğrencilerin günlük ortalama internet kullanma süresinin $3,56 \pm 1,74$ saat olduğunu bulmuştur [22]. Öğrencilerin internet kullanım alışkanlıkları benzerlik gösterdiği söylenebilir.

Araştırmamızdaki öğrencilerin \%47,4'ü yapay zeka kavramı hakkında bilgi sahibi olduğunu ifade ederken, \%34,8'i yapay zekanın sağlıkta kullanımı hakkında bilgi sahibi olduğunu bildirmiştir. Öğrencilerin büyük çoğunluğu (\%92'si) bu bilgileri sosyal medyadan edindiğini ifade etmiştir. Benzer şekilde üniversite öğrencilerinin yapay zeka konusunda algı ve görüşlerini inceleyen diğer çalışmalarda, öğrencilerin yapay zeka kavramı hakkında bilgiyi sosyal medya yolu ile edindiği bulunmuştuR $[22,23]$. Bu durum yapay zekanın son yıllarda pek çok alana daha yoğun bir şekilde girmiş olmasıyla medyada daha geniş yer bulmasından kaynaklanıyor olabileceği şeklinde yorumlanabilir. Çalışmamızdaki öğrencilerin çoğunluğu sağlık alanında yapay zeka ile ilgili gelişmelerden heyecan duyduklarını ve kendi mesleklerine yönelik yapay zeka ile ilgili gelişmeleri takip etmenin önemli olduğunu düşünmektedir. Öğrencilerin meslekleri ile ilgili yapay zeka gelişmelerine ilgi duymasının da bu sonucu etkilemiş olabileceği düşünülmektedir.

Çalışmamızda yer alan sağlık bilimleri öğrencilerinin yapay zeka uygulamalarıın mesleki becerilerini zenginleştireceği ve yapay zeka kullanarak hastalara daha iyi sağlık hizmeti sunabileceğine ilişkin görüşleri öne çıkmıştır. Ayrıca öğrencilerin çoğunluğu, yapay zekanın karar desteği verme, insanların ne hissettiklerini tahmin edebilme ve kendi kendine öğrenme özelliklerinin mesleğini uygularken kolaylık sağlayacağını düşünmektedir. Literatürde ilgili çalışmalar incelendiğinde, tıp fakültesi öğrencilerinin hekimlik kariyerlerinde yapay zekayı kullanmak istedikleri ve sağlıkta yapay zeka uygulamalarının mesleğini uygularken kolaylık sağlayacağına yönelik görüş sundukları görülmüştür [22,24]. Yapay zeka teknolojileri ilk olarak genç bireyler tarafından kabul görmektedir. Bu durum genç bireylerin teknoloji kullanımına aşina olmaları ile ilişkilendirilmektedir [3]. Çalışmamızda da öğrencilerin çalışma ortamlarında yapay zeka kullanılmasına yönelik istekli oldukları görülmektedir. Geleceğin sağlık profesyonellerinin yapay zeka teknolojisi kullanımına yönelik olumlu tutumları sağlık alanında bu teknolojinin şekillenmesine etki edeceği düşünülmektedir. 
Sağlıkta yapay zeka uygulamaları tanı koymada ya da tedavi planlamada tıbbi hatalar sorununu büyük ölçüde çözmek ve verimliliği artırmak için kullanılan malpraktis oranını azaltıcı rolü olan imkanlar sunabilmektedir [10]. Araştırmamızdaki öğrencilerin çoğunluğu, yapay zeka sistemlerinin tıbbi hata yapma riskini azalttığı yönünde görüş bildirmiştir. Yapay zeka teknolojisinin klinik uygulamadaki hataların sayısını azaltabileceği öngörülse de; tanısal ya da karar verici yapay zeka araçlarının etkisinin, hasta sonuçları üzerindeki etkisiyle değerlendirilmesini gerekmektedir. Yapay zeka uygulamaları sonucu oluşabilecek hatalı tıbbi uygulamaların ve bunun getireceği sonuçlarının sorumlusunun kim olacağına ilişkin etik boyut tartışmaları sağlıkta yapay zeka kullanımına yönelik önemli tartışma konularından biridir [4,5,8,9]. Nitekim çalışmamızdaki öğrencilerin çoğunluğu yapay zeka sistemlerinin, kendilerine öğretilmediği sürece etik anlayışlarının olmadığı görüşündedir. Kanada'da tıp fakültesi öğrencileri ile yapılan bir çalışmada, katılımcı öğrencilerin büyük çoğunluğu yapay zekanın yeni etik zorluklar ortaya çıkaracağı görüşünü bildirmiştir [25]. Geleceğin sağlık profesyonelleri olarak, öğrencilerinin teknolojik gelişmeler yoluyla hassas ve örselenebilir popülasyonları korumak için hasta savunuculuğu rollerini ön planda tutmaları gerekecektir [12]. Bu nedenle tıp ve sağlık bilimleri öğrencilerinin etik sorunları nasıl yönetileceğine dair teorik eğitim ve vaka örneklerine içeren müfredat planlamaları, öğrencilerin yapay zeka teknolojinin getirebileceği potansiyel etik sorunların farkında olmalarını sağlayabilir.

Araştırmamızdaki öğrencilerin çoğunluğu, yapay zekanın kullanımın artıyor olmasının gelecekte sağlık çalışanlarına olan intiyacı azaltacağına ve bu durumun iş bulma kaygısı yaşamasına neden olacağını düşünmektedir. Anketin açık uçlu sorular bölümüne verilen öğrenci yanıtlarının tematik analizi, öğrencilerin sağlıkta yapay zeka kullanımına ilişkin olumlu ve olumsuz yönde farklı düşüncelere sahip olduğunu, gelecekteki uygulamalara yönelik endişeler taşıdıklarını göstermiştir. Literatürde, tıp ve sağlık bilimleri öğrencilerin de bu endişeleri taşıdığı bulunmuştur [22,24-26]. Son dönemde robotlar yüzünden insanların işlerini kaybedecek olması düşüncesi yapay zeka teknolojisini hakkında en büyük endişelerden biri olarak görülmektedir. Robotların iş hayatına girmesiyle işsizliğin artacağı, üretim sektöründeki otomasyonun işi insanlardan daha pratik yapabileceği yönünde öngörüler vardır [26]. Nitekim, araştırmamızda yer alan öğrencilerin çoğunluğu "Yapay zeka ifadesi bana robot sistemleri çağrıştırmaktadır” ifadesine katılmıştır. Bu bulgular, sağlık bilimleri fakültesi öğrencilerini gelecekteki yapay zeka uygulamaları ve sağıkta kullanımı konusunda farkındalıklarını arttırma noktasında eğitim alabilmelerini sağlamak için mevcut müfredat öğelerinin gözden geçirilmesinin önemini doğrulamaktadır [23].

Araştırmamızda yer alan öğrenciler, sağlıkta yapay zeka kullanımına yönelik bazı uygulama önerilerinde bulunmuşlardır. Öğrencilerin vermiş olduğu öneriler; tıbbi hataların önlenmesine yönelik uygulamalar, klinik karar vermeyi kolaylaştıracak uygulamalar, hastaların hislerini ve düşüncelerini anlamaya yardımcı olabilecek uygulamalar, hasta takip uygulamaları, hastaların kullanımına yönelik hatırlatıcı uygulamalar, sağlık profesyonellerinin iş yükünü azaltmaya yardımcı uygulamalar ve robotik uygulamalar olarak gruplandırımıştır. Yapay zekanın geliştirilmesinde özellikle tıbbi hataların önüne geçmek için çalışamalar bulunmaktadır [27-29]. Klinik karar desteği [30,31] ve hasta takip uygulamaları [32] da yapay zekanın odaklandığı alanlar arasındadır. Geleceğin sağlık profesyonellerinin üstlendikleri yeni rolleri yerine getirebilmeleri için yenilikçi ve girişimci bakış açısına sahip olmaları önemlidir.

Araştırmamızda yer alan öğrenciler, kendi kendine öğrenen yapay zeka uygulaması geliştirmeye ilgisi olduğu yönünde görüş bildirmiştir. Öğrencilerin görüşleri gelecekteki sağık hizmetlerinde kullanılacak yapay zeka araçlarının tasarımına ve uygulanmasına yön verebilir. Öğrencilerin bu potansiyelini kullanabilmesi için eğitimcilere önemli görevler düşmektedir. Yapay zeka odaklı ders içeriklerini öğretmenin donanımlı eğitimciler gerektirdiği göz önünde bulundurulması gereken bir diğer noktadır. Bu nedenle, eğitimcilerin de yapay zeka ve sağlıkta yapay konusunda farkındalık ya da kendilerini yeterli hissetmelerine dair çalışmaların yapılmasına gereksinim vardır.

\section{Sonuç}

Yapay zekanın, tanı, tedavi, bakım, araştırma ve eğitim dahil olmak üzere sağlık hizmetinin çeşitli alanlarını etkilemesi öngörülmektedir. Sağlık bilimleri fakültesi öğrencilerinin sağlıkta yapay zeka hakkındaki görüşlerini inceleyen bu araştırma sonucunda, sağlık bilimleri fakültesi öğrencilerinin yapay zeka ve sağlıkta yapay zeka uygulamalarının ve bu uygulamaların gelecekte kendi mesleklerini etkileyebilecek dinamiklerin farkında olduğu bulunmuştur. Yapay zeka destekli teknolojiler sağlık hizmetlerine giderek daha fazla entegre edildiğinden, yüksek kaliteli hasta bakımı sunabilen yetkin sağlık profesyonelleri yetiştirmeye devam etmek için sağlık bilimleri eğitim programına uyum sağlamasına gereksinim vardır. Bu sayede öğrencilerin teknoloji kullanma yeterliklerine katkı sağlanabilir. Gelecekte karşılaşacakları yapay zeka teknolojilerinin klinik ortamda etkin kullanımına 
yönelik hazır bulunuşlukları artııılarak, daha etkin hasta bakımına katkıda bulunmalarına fırsatlar yaratılmalıdır. Yapay zekanın gelecekteki sağlık hizmeti üzerindeki olumlu ya da olumsuz araştırmak için ülkemizde konu ile ilgili daha fazla araştırma yapılmalıdır. Sağlık bilimleri alanında öğrenim gören öğrencilerin yapay zeka konusundaki görüş ve öngörülerinin alınması bu çalışmalara katkı sağlayabilir. Öğrencilerin eğitimde yapay zeka destekli teknolojileri kullanmasına fırsatlar sunularak öğrenci merkezli yapay zeka teknolojilerinin etkinliği sınanabilir.

\section{Teşekkür}

Araştırmaya katılan tüm öğrencilerimize teşekkür ederiz. Veri toplama aracının geliştirilmesinde destek veren tüm uzmanlarımıza teşekkür ederiz.

\section{Kaynakça}

[1] McCarthy J. What is Artificial Intelligence? [Internet]. 2007 [cited 2020 May 5]. Available from: http://wwwformal.stanford.edu/jmc/whatisai/

[2] Rajkomar A, Dean J, Kohane I. Machine Learning in Medicine. N Engl J Med [Internet]. 2019 Apr 3 [cited 2020 Dec 29]; Available from: https://www.nejm.org/doi/10.1056/NEJMra1814259

[3] Sucu I. Yapay Zekanın Toplum Üzerindeki Etkisi ve Yapay Zeka (A.I.) Filmi Bağlamında Yapay Zekaya Bakış. Uluslar Kitapları Ve Eğitim Materyalleri Derg. 2019 Dec 16;2(2):203-15.

[4] Yu K-H, Beam AL, Kohane IS. Artificial intelligence in healthcare. Nat Biomed Eng. 2018 Oct;2(10):719-31.

[5] Reddy S, Fox J, Purohit MP. Artificial intelligence-enabled healthcare delivery. J R Soc Med. 2019 Jan;112(1):22-8.

[6] Baker A, Perov Y, Middleton K, Baxter J, Mullarkey D, Sangar D, et al. A Comparison of Artificial Intelligence and Human Doctors for the Purpose of Triage and Diagnosis. Front Artif Intell. 2020;3:543405.

[7] Zhou L-Q, Wang J-Y, Yu S-Y, Wu G-G, Wei Q, Deng Y-B, et al. Artificial intelligence in medical imaging of the liver. World J Gastroenterol. 2019 Feb 14;25(6):672-82.

[8] Jiang F, Jiang Y, Zhi H, Dong Y, Li H, Ma S, et al. Artificial intelligence in healthcare: past, present and future. Stroke Vasc Neurol. 2017 Dec;2(4):230-43.

[9] Maddox TM, Rumsfeld JS, Payne PRO. Questions for Artificial Intelligence in Health Care. JAMA. 2019 Jan $1 ; 321(1): 31-2$.

[10] Çalişkan SA, Demir K, Karaca O. Sağlık Çalışanları Yapay Zekaya Hazır Mı? Are Healthcare Workers Ready for Artificial Intelligence? Sağlık Bilim Yapay Zeka Derg J Artif Intell Health Sci ISSN2757-9646. 2021 Apr 15;1(1):35-35.

[11] Abhinav GVKS, Subrahmanyam SN. Artificial Intelligence in Healthcare. J Drug Deliv Ther. 2019 Oct 15;9(5s):164-6.

[12] Topol E. The Topol Review: Preparing the healthcare workforce to deliver the digital future [Internet]. National Health Service; 2017 [cited 2021 Mar 1]. Available from: https://topol.hee.nhs.uk/wp-content/uploads/HEETopol-Review-2019.pdf

[13] Reznick R, Harris K, Horsley T, Sheikh Hassani M. Task Force Report on Artificial Intelligence and Emerging Digital Technologies [Internet]. Royal College of Physicians and Surgeons of Canada; 2020 [cited 2021 Feb 2]. Available from: https://www.royalcollege.ca/rcsite/health-policy/initiatives/ai-task-force-e

[14] United States Agency for International Development. Artificial Intelligence in Global Health: Defining a Collective Path Forward [Internet]. 2019 Apr [cited 2021 Mar 3]. Available from: https://www.usaid.gov/cii/aiin-global-health

[15] Ngo B, Nguyen D, vanSonnenberg E. Artificial Intelligence: Has Its Time Come for Inclusion in Medical School Education? Maybe...Maybe Not. MedEdPublish [Internet]. 2021 May 16 [cited 2021 May 16];10. Available from: https://www.mededpublish.org/manuscripts/3811 
[16] Fan KY, Hu R, Singla R. Introductory machine learning for medical students: A pilot. Med Educ. 2020;54(11):1042-3.

[17] Yun D, Xiang Y, Liu Z, Lin D, Zhao L, Guo C, et al. Attitudes towards medical artificial intelligence talent cultivation: an online survey study. Ann Transl Med. 2020 Jun;8(11).

[18] dos Santos DP, Giese D, Brodehl S, Chon SH, Staab W, Kleinert R, et al. Medical students' attitude towards artificial intelligence: a multicentre survey. Eur Radiol. 2019 Apr;29(4):1640-6.

[19] IBM. IBM SPSS Statistics for Windows, Version 26.0. Armonk, NY: IBM Corp; 2019.

[20] Grzeska A, Ali S, Szmuda T, Słoniewski P. Objective Outcomes Evaluation of Innovative Digital Health Curricula. Comment on "Undergraduate Medical Competencies in Digital Health and Curricular Module Development: Mixed Methods Study." J Med Internet Res. 2021 May 28;23(5):e26034.

[21] 15. TiK (TUiK). Hanehalkı Bilişim Teknolojileri Kullanım Araştırması [Internet]. [cited 2021 Jan 1]. Available from: https://data.tuik.gov.tr/Bulten/Index?p=Hanehalki-Bilisim-Teknolojileri-(BT)-Kullanim-Arastirmasi2020-33679

[22] Öcal EE, Atay E, Önsüz MF, Algin F, Çokyiğit FK, Kilinç S, et al. Tıp Fakültesi Öğrencilerinin Tıpta Yapay Zeka ile İlgili Düşünceleri. Türk Tıp Öğrencileri Araşt Derg. 2020 May 12;2(1):9-16.

[23] Chao P-J, Hsu T-H, Liu T-P, Cheng Y-H. Knowledge of and Competence in Artificial Intelligence: Perspectives of Vietnamese Digital-Native Students. IEEE Access. 2021;9:75751-60.

[24] Abid S, Awan B, Ismail T, Sarwar N, Sarwar G, Tariq M, et al. Artificial Intelligence: Medical Student's Attitude in Distric Peshawar Pakistan. Pak J Public Health. 2019 Jul 13;9(1):19-21.

[25] Mehta N, Harish V, Bilimoria K, Morgado F, Ginsburg S, Law M, et al. Knowledge and Attitudes on Artificial Intelligence in Healthcare: A Provincial Survey Study of Medical Students. MedEdPublish. 2021 Mar 25;10.

[26] Doğaner A. The Approaches and Expectations of The Health Sciences Students Towards Artificial Intelligence. Karya J Health Sci. 2021 Apr 30;2(1):5-11.

[27] Miller DD, Brown EW. Artificial Intelligence in Medical Practice: The Question to the Answer? Am J Med. 2018 Feb 1;131(2):129-33.

[28] Challen R, Denny J, Pitt M, Gompels L, Edwards T, Tsaneva-Atanasova K. Artificial intelligence, bias and clinical safety. BMJ Qual Saf. 2019 Mar 1;28(3):231-7.

[29] Corny J, Rajkumar A, Martin O, Dode X, Lajonchère J-P, Billuart O, et al. A machine learning-based clinical decision support system to identify prescriptions with a high risk of medication error. J Am Med Inform Assoc. 2020 Nov 1;27(11):1688-94.

[30] Buchlak QD, Esmaili N, Leveque J-C, Farrokhi F, Bennett C, Piccardi M, et al. Machine learning applications to clinical decision support in neurosurgery: an artificial intelligence augmented systematic review. Neurosurg Rev. 2020 Oct 1;43(5):1235-53.

[31] Shortliffe EH, Sepúlveda MJ. Clinical Decision Support in the Era of Artificial Intelligence. JAMA. 2018 Dec 4;320(21):2199-200.

[32] Kobayashi N, Shiga T, Ikumi S, Watanabe K, Murakami H, Yamauchi M. Semi-automated tracking of pain in critical care patients using artificial intelligence: a retrospective observational study. Sci Rep. 2021 Mar 4;11(1):5229. 